Running head: BOUNDARIES OF AMERICAN IDENTITY

\title{
Boundaries of American Identity: \\ Relations between Ethnic Group Prototypicality and Policy Attitudes
}

\author{
Que-Lam Huynh \\ California State University, Northridge \\ Thierry Devos and Hannah R. Altman \\ San Diego State University
}

This is a postprint/accepted version of the manuscript. It is now published:

Huynh, Q.-L., Devos, T., \& Altman, H. (2015). Boundaries of American identity: Relations between ethnic group prototypicality and policy attitudes. Political Psychology, 36, 449-468. https://doi.org/10.1111/pops.12189

Please cite the published version. The version available on PsyArXiv is before journal proof. The published version might be slightly different.

This research was supported in part by National Institute of Mental Health Grants R24

MH 065515 and 3R24 MH 065515-06S1.

Correspondence concerning this article should be addressed to Que-Lam Huynh, Department of Psychology, California State University, Northridge, 18111 Nordhoff Avenue, Northridge, CA 91330-8255. E-mail: huynh.quelam@gmail.com

Keywords: American identity; ethnic group prototypicality; relative ingroup prototypicality; policy attitudes; acculturation ideologies 


\begin{abstract}
We sought to document that the extent to which different ethnic groups are perceived as embodying the American identity is more strongly linked to anti-minority policy attitudes and acculturation ideologies among majority group members (European Americans) than among minority group members (Asian Americans or Latino/as). Participants rated 13 attributes of the American identity as they pertain to different ethnic groups, and reported their endorsement of policy attitudes and acculturation ideologies. We found a relative consensus across ethnic groups regarding defining components of the American identity. However, European Americans were perceived as more prototypical of this American identity than ethnic minorities, especially by European American raters. Moreover, for European Americans but not for ethnic minorities, relative ingroup prototypicality was related to anti-minority policy attitudes and acculturation ideologies. These findings suggest that for European Americans, perceptions of ethnic group prototypicality fulfill an instrumental function linked to preserving their group interests and limiting the rights afforded to ethnic minorities.
\end{abstract}


Boundaries of American Identity:

Relations between Ethnic Group Prototypicality and Policy Attitudes

The US is a nation of immigrants and boasts remarkable ethnic and racial diversity, yet issues of exclusion have shaped the nation since its inception. Even today, one particular form of exclusion is the propensity to view members of ethnic minority groups as less "American" than European Americans (Devos \& Banaji, 2005). Here, our goal was to determine whether this propensity to view European Americans as being more aligned with the American identity than Asian Americans or Latino/as is linked to attitudes and beliefs delineating the rights of and opportunities for these ethnic minority groups. An important and novel contribution of the current investigation was to examine this issue from the perspective of different ethnic groups. We sought to document that perceptions of ethnic group prototypicality differ and fulfill different functions for ethnic majority group members than for ethnic minority group members. More precisely, we tested the idea that the extent to which different ethnic groups are perceived as embodying the American identity is more strongly linked to anti-minority policy attitudes and acculturation ideologies among European Americans than among Asian Americans or Latino/as.

\section{Lay Definitions of American Identity}

Prior to investigating the extent to which different ethnic groups are seen as "American," it is important to examine how the American identity is defined and to determine whether this definition is shared across ethnic lines. Although various terms or labels have been used to distinguish key facets of lay definitions of the American identity, three components have emerged with some regularity (Citrin, Haas, Muste, \& Reingold, 1994; Citrin, Reingold, \& Green, 1990; Devos \& Banaji, 2005; Schildkraut, 2007; Wright, Citrin, \& Wand, 2012). Liberal political principles encompass universalistic values such as social equality, self-reliance, liberty, 
and democracy. These core principles also are in line with a civic construction of national identity (Mukherjee, Molina, \& Adams, 2012; Pehrson \& Green, 2010). Attachment to the nation includes emotional ties to America, such as patriotism and defending the country when it is criticized. Attachment to the nation refers here to characteristics that make perceivers deem someone as more or less American, but this component is distinct from patriotism or nationalism (Schatz, Staub, \& Lavine, 1999; Sidanius, Feshbach, Levin, \& Pratto, 1997), which are different forms of group attachment (Schildkraut, 2007). Finally, nativism includes more exclusionary attributes, such as speaking English or believing in the Christian god. These characteristics also are referred to as cultural or primordial constructions of national identity (Mukherjee et al., 2012; Pehrson \& Green, 2010).

These three facets draw the boundaries of the American identity in that they, more or less explicitly, define the criteria for inclusion in the national identity. Based on work by TheissMorse (2009), boundaries of national identity can be conceptualized as relatively soft or hard. Liberal political principles and emotional attachment to the nation correspond to soft boundaries in that they are more subjective or less definitive - they essentially are based on beliefs. In contrast, an emphasis on nativist elements, including the importance of being born in the US or of speaking English, are hard boundaries in that they are more impermeable and strict. This distinction provides a parsimonious way of capturing two contrasting conceptions of what it means to be American.

The picture emerging from previous research suggests that there is a relative consensus on what it means to be an American, which is to share a commitment to liberal political principles and an emotional attachment to the nation (soft boundaries), and to a lesser extent, to be a part of a culturally homogeneous group (hard boundaries; Citrin et al., 1990, 1994; Devos \& 
Banaji, 2005; Schildkraut, 2007; Wright et al., 2012). However, the notion that Americans from different ethnic or racial backgrounds share a common perspective regarding the defining attributes that make up the national identity has not been formally tested. An initial and valuable step of our approach was to examine systematically the extent to which members of different ethnic groups shared a common definition of the American identity and made the distinction between soft and hard delineations of the national identity. From a theoretical standpoint, a relative agreement between majority and minority group members on what it means to be American would substantiate the idea that perceived differences between groups holding asymmetrical positions (such as ethnic groups in the US) acquire meaning because these perceptions are anchored in a common frame of reference (Deschamps, 1982). Relatively stable group-based hierarchies, whether they are defined based on differences in terms of power, social, or numerical status, presuppose that members of groups holding distinct positions in the hierarchy subscribe to a common definition of what is ideal or normative. Differences become meaningful and legitimized to the extent that these various groups have shared understanding of normative principles, values, or attributes that transcend group lines. Thus, we expected to find a relative agreement on the importance of identity boundaries among members of different ethnic groups. Across ethnic lines, soft boundaries are more likely to be endorsed than hard boundaries, but the latter are likely to be endorsed to some extent. Despite this relative agreement, one also would expect reliable and meaningful differences to emerge between ethnic majority and minority groups in their understanding of what it means to be a true American. These differences in lay definitions may reflect a relatively ethnocentric perspective or may be consistent with group interests. At the same time, it is important to document that perceived differences between ethnic groups are constrained and anchored in a socially-constructed definition of the American 
identity that, at least to some extent, transcends ethnic lines.

\section{Perceived Prototypicality of Ethnic Groups}

Having captured the content and structure of lay definitions of the American identity, we now consider theoretical principles that would account for the extent to which different ethnic groups are perceived as fitting into such definitions. Two theoretical perspectives address most directly this research question. First, according to social dominance theory (Sidanius \& Pratto, 1999), the dominant group in a multiethnic society usually comes to regard itself as having ownership of the nation, its resources, and its symbols; consequently, minority status entails a certain degree of exclusion from the national identity (Sidanius et al., 1997; Sidanius \& Petrocik, 2001). Although Asian Americans and Latino/as, as compared to African Americans, may be excluded from the American identity to a lesser extent and may be able to assimilate into the larger society over successive generations [see work by Sears \& Savalei (2006) on "black exceptionalism"], social dominance theory suggests that all ethnic minority groups would be excluded from the mainstream to some extent. From this perspective, European Americans may enjoy a greater sense of "Americanness," and ethnic minority group members may be excluded or marginalized from this identity, especially by dominant group members.

Second, the ingroup projection model accounts for the role of ingroup and outgroup perceptions in explaining the relative exclusion of certain groups from a superordinate identity. The model starts with an assumption, based on self-categorization theory (Turner, Hogg, Oakes, Reicher, \& Wetherell, 1987), that social groups are appraised in reference to a higher level, superordinate identity (Mummendey \& Wenzel, 1999; Wenzel, Mummendey, \& Waldzus, 2007). Further, people may define this superordinate identity in terms of their ingroup's characteristics or attributes, thus creating a prototype of the superordinate identity that is based 
on these generalized ingroup attributes. When outgroup members are evaluated based on this prototype, they tend to be seen as not fitting the superordinate identity as well as ingroup members. Moreover, the tendency to perceive the ingroup as more prototypical of the superordinate category than an outgroup is more pronounced for majority than for minority group members (Waldzus, Mummendey, Wenzel, \& Boettcher, 2004).

In sum, although the first perspective places emphasis on the role of group-based hierarchies and the second focuses more on the impact of ingroup vs. outgroup distinctions, combining these principles allows us to generate straightforward predictions regarding the relative perceived prototypicality of ethnic groups and the extent to which these perceptions differ as a function of group membership. We should expect European Americans to perceive themselves as more prototypically American than Asian Americans and Latino/as (i.e., exhibit a strong ingroup prototypicality effect). In contrast, Asian Americans and Latino/as should display ingroup prototypicality effects to a smaller extent, given that socio-structural realities sustain the opposite perception: that they are less “American" than European Americans.

In line with this proposition, research conducted in the US revealed that the propensity to more readily ascribe the American identity to European Americans than to ethnic minorities on implicit measures was more pronounced among European American participants than among Asian American or Latino/a participants (Devos \& Banaji, 2005; Devos, Gavin, \& Quintana, 2010). The goal of the present research was to extend this work by focusing on self-reported perceptions of ethnic group prototypicality and by examining the extent to which ethnic groups were differentiated on the core components of the American identity discussed earlier (hard and soft boundaries). Doing so should allow us to determine whether the propensity of European Americans to display an ingroup prototypicality effect is limited to characteristics that are, for 
socio-historical reasons, more likely to reflect the socio-demographic realities of their group, or whether the effect is more generic in that it manifests itself irrespective of the dimensions on which the groups are compared. More precisely, it could be argued that it is not very surprising that characteristics regrouped under the umbrella of hard boundaries (e.g., being born in the US or speaking English) are more easily associated with European Americans than with Asian Americans or Latino/as. The ingroup prototypicality effect would be more counterintuitive if it generalizes to soft boundaries that include characteristics a priori less biased toward European Americans, in particular when it comes to liberal political principles. In other words, if a standard for group membership carries the ideological justification of inequality in its contents, there is hardly any surprise if those not fitting the standard are treated differently than those fitting it. However, if what matters more is the more general concept of relative group prototypicality, the content of the American identity can fluctuate without necessarily ensuring a greater inclusion of ethnic minority groups in the national identity.

\section{Ethnic Group Prototypicality, Policy Attitudes, and Acculturation Ideologies}

As stated above, perceptions of group prototypicality may reflect or be constrained by socio-structural realities. In addition, they may serve instrumental functions in that they help to meet a desired goal or to justify a given state. Eloquently, Sindic and Reicher (2008) developed the idea that there might be a variety of instrumental reasons for emphasizing or downplaying the relative prototypicality of the ingroup over the outgroup. In this context, instrumentality concerns are linked to actors' interests as group members. Under some circumstances, group members are likely to construe a situation in a manner that contributes to achieve, preserve, or claim collective interests. For European Americans, emphasizing the relative prototypicality of their ethnic group may be linked to attitudes that legitimize status differences (i.e., symbolic group interests), 
maintain control over the governing structures, and deny rights, resources, or opportunities to ethnic minority groups (i.e., realistic group interests). For ethnic minority group members, asserting that their group is at least as American as the majority group may be tied to attitudes that challenge existing status differences. Alternatively, downplaying the ingroup's prototypicality might be a way to strategically draw attention to its marginalization. In other words, perceptions of group prototypicality may be used differently or possibly fulfill distinct instrumental functions for majority and minority group members. At a minimum, one would expect that the relations between group prototypicality perceptions and relevant policy attitudes or belief systems differ depending on perceivers' position in the social system (i.e., majority vs. minority perspectives).

Prior research has documented that perceiving one's ingroup as more prototypical of the superordinate category than outgroups accounts for negative emotional reactions and unfavorable behavioral intentions toward outgroups (Kessler, Mummendey, et al., 2010; Reese, Berthold, \& Steffens, 2012; Waldzus, Mummendey, \& Wenzel, 2005; Weber, Mummendey, \& Waldzus, 2002; Wenzel, Mummendey, Weber, \& Waldzus, 2003). To our knowledge, the potential implications of relative group prototypicality have not been examined in the context of ethnic relations in the US. Moreover, the bulk of dependent variables considered so far captures evaluative or affective responses directed toward outgroups. We examined the extent to which perceptions of group prototypicality are linked to policy attitudes and acculturation ideologies that delineate the rights and opportunities for minority group members. Finally, with one notable exception (Sindic \& Reicher, 2008), past research examined the implications of perceived group prototypicality from the perspective of the majority or dominant group. For the first time, we directly compared the predictive power of perceived group prototypicality for majority and 
minority group members. Based on the instrumental functions of intergroup perceptions discussed earlier, we would expect that relative ingroup prototypicality is more likely linked to attitudes and beliefs curtailing the rights and opportunities of ethnic minority groups among respondents who belong to the ethnic majority group. If European Americans view ethnic minorities as being relatively atypical of the American identity, they may be unsupportive of prominority policies or ideologies because they view ethnic minority groups as marginalized fractions of the population who should not enjoy the benefits of full group membership. We examine this issue by focusing on a range of policy attitudes relevant to ethnic relations in the US (immigration, language policy, affirmative action, and ethnic representation; Sears, Citrin, Cheleden, \& van Laar, 1999), some of which have been shown to be related to the definition of American identity (Citrin et al., 1994; Li \& Brewer, 2004), but never studied in relation to ethnic group prototypicality. Additionally, we examined the links between ethnic group prototypicality and two acculturation ideologies (assimilation and multiculturalism) that are often defined as alternative solutions for how an ethnically diverse society should function (Citrin et al., 1994; Ryan, Hunt, Weible, Peterson, \& Casas, 2007; Wolsko, Park, \& Judd, 2006). Advocates of assimilation suggest that Americans should embrace the traditional melting pot ideal, whereby people from diverse backgrounds relinquish their ethnic identities and customs in exchange for membership within American society. Advocates of multiculturalism suggest that ethnic and cultural differences should be recognized, celebrated, and incorporated into mainstream American society. Recent research lends support to the notion that assimilation is akin to a hierarchy-enhancing perspective, whereas multiculturalism has hierarchy-attenuating properties (Levin et al., 2012). Given that these specific policies and acculturation ideologies have contrasting implications for the interests of majority and minority ethnic groups, we examined 
whether their endorsement was linked to the perceived prototypicality of ethnic groups and whether these interconnections differed as a function of respondents' ethnicity.

\section{Hypotheses}

In sum, we extended previous work on the American identity by systematically examining characteristics of the "true American" as understood by various ethnic groups. Then, using the framework of relative ingroup prototypicality, we examined the links between prototypicality and policy attitudes and acculturation ideologies. By considering the distinction between hard vs. soft boundaries of the American identity, we can determine whether the predicted patterns are relatively content-specific vs. more generic. To recap, our hypotheses were as follows:

1. There should be a relative consensus across ethnic groups on the definition of the American identity. More precisely, the different attributes associated with the American identity should be rank-ordered similarly by participants from different ethnic groups. In addition, across ethnic groups, there should be consistency in terms of the factor structure underlying lay definitions of the American identity with a clear distinction between hard and soft boundaries.

2. Perceptions of the relative prototypicality of ethnic groups should differ as a function of participants' ethnicity. More precisely, European American participants should perceive their ingroup to be relatively more prototypical of the American superordinate category than an ethnic minority group, whereas perceptions of relative ingroup prototypicality should be weaker for Asian American and Latino/a participants. This hypothesis will be tested by examining relative prototypicality ratings on both hard and soft boundaries to determine whether the effects are content-specific or not.

3. The relationships between relative ingroup prototypicality and policy attitudes or 
acculturation ideologies should be stronger for majority than for minority group members. For European American participants, relative ingroup prototypicality should account for the endorsement of policy attitudes and ideologies hindering the rights and opportunities of ethnic minorities. For Asian American and Latino/a participants, it should be a smaller and nonsignificant predictor of these policy attitudes and acculturation ideologies.

\section{Method}

\section{Participants}

Participants in Sample A were 182 Asian Americans and 179 European Americans, and participants in Sample B were 219 Latino/as and 227 European Americans. All participants were undergraduate students from a large, public university on the West Coast of the US. Samples A and B were collected over the same time period, but they differed in terms of the ethnicity of the target groups rated. Specifically, participants in Sample A rated the prototypicality of Asian Americans and European Americans, whereas participants in Sample B rated the prototypicality of Latino Americans and Caucasian Americans (see Measures for more details). Because of the relative difficulty of recruiting African American participants on the campus, we did not include this ethnic group in our study (for research on African Americans' perceptions of the American identity, see Devos \& Banaji, 2005; Huynh, Devos, \& Smalarz, 2011). The samples were comparable in gender composition, citizenship status, generation status, mean age, and year in school (see Table 1 for complete participant demographics by sample and ethnicity).

\section{Procedure}

Participants were recruited through the psychology department subject pool and received partial course credit for participation. They completed all measures on a computer in small groups of up to 4 . 


\section{Measures}

All participants completed a series of measures that allowed us to assess beliefs about the American identity and perceived prototypicality of different ethnic groups. A subset of participants (Sample A: $n=135$ Asian Americans, $n=111$ European Americans; Sample B: $n=$ 103 Latino/as, $n=95$ European Americans) also responded to items regarding policy attitudes and acculturation ideologies. ${ }^{1}$ A different subset of participants from Sample B $(n=63$ Latino/as and $n=77$ European Americans) completed a measure of social dominance orientation but not the measures of policy attitudes and ideologies. Measures were completed in the order outlined below.

Definition of the American identity and perceived ethnic group prototypicality. To assess the defining attributes of the American identity and perceived ethnic group prototypicality, we relied on 13 core qualities used successfully in previous research and covering endorsement of civic values, emotional attachment to America, and nativism (Table 2; Citrin et al., 1990, 1994; Devos \& Banaji, 2005).

First, participants rated their own ethnic group and another group on these 13 attributes (e.g., "Most Asian Americans treat people of all races and backgrounds equally"). The target ethnic groups were labeled European Americans and Asian Americans for Sample A, and Caucasian Americans and Latino Americans for sample B. ${ }^{2}$ After making these ratings, they indicated the extent to which these 13 attributes characterized a "true American" (e.g., "To be a true American, it is important to treat people of all races and backgrounds equally"). Thus, participants made a total of 39 ratings (13 attributes $\times 3$ target groups). Responses were provided on 7-point Likert-type scales $(1=$ strongly disagree to $7=$ strongly agree $)$. The order of the target ethnic groups and attributes were randomized. 
Policy attitudes. A subset of participants also completed measures of policy attitudes. We adapted 23 items from the General Social Survey to assess the extent to which participants support or oppose four policies relevant to ethnic relations in the US, particularly those that either promote or hinder the rights and opportunities of ethnic minorities (Sears et al., 1999). The immigration measure (6 items) assessed the degree to which participants agreed that immigrants should be welcomed and afforded equal rights as American citizens. The language policy measure ( 7 items) assessed the extent to which participants agreed that languages other than English can be used in conducting government business. The affirmative action measure (5 items) assessed the extent to which participants agreed that ethnic minorities should be given special treatment or preference. The ethnic representation measure ( 5 items) assessed the role of ethnicity in public life and in particular, the importance of ethnic representation in governmental and educational institutions.

Acculturation ideologies. The same participants also completed a series of items assessing the extent to which they endorse two contrasting acculturation ideologies (Wolsko et al., 2006). The assimilation measure (6 items) assessed the extent to which participants agreed that minority group members should relinquish their ethnic heritage and adopt mainstream American culture to achieve social harmony. The multiculturalism measure (6 items) assessed the extent to which participants agreed that Americans should recognize and appreciate the different but equally valid attributes of different ethnic groups to achieve social harmony.

The policy attitudes and acculturation ideologies items were intermixed, and the order of items was randomized. Responses for both scales were provided on the same 5-point Likert-type scales $(1=$ strongly disagree to $5=$ strongly agree $)$. Higher scores indicate stronger endorsement of the policy or ideology. 
Social dominance orientation. An additional subset of Sample B participants-different from those who completed the aforementioned policy items - completed the social dominance orientation scale (SDO; Pratto, Sidanius, Stallworth, \& Malle, 1994). This 16-item scale measures the degree of preference for inequality or hierarchy among social groups. Responses were provided on 5-point Likert-type scales $(1=$ strongly disagree to $5=$ strongly agree $)$. See Table 3 for descriptive statistics for all measures.

\section{Results}

\section{Hypothesis 1: Common Definition of the American Identity}

To test our first hypothesis that there would be a relative consensus on the definition of the American identity across groups of respondents defined based on self-reported ethnicity, we examined rankings of mean ratings for the 13 items across the 4 groups of raters (see Table 2). Kendall's coefficient of concordance revealed a strong degree of agreement in these rankings across all four groups of raters, $W=.96, \chi^{2}(12)=45.89, p=.000007$. This suggests that there was strong consensus about the defining characteristics of the American identity across ethnic groups.

Next, we conducted confirmatory factor analyses (using Mplus 5.1 software; Muthén \& Muthén, 2007) to test whether the factor structure of American identity was consistent across ethnic groups (we combined data from European Americans in Samples A and B in these analyses). We tested a three-factor model with soft boundaries ( 7 items: treated equally, respect institutions, vote, own effort, feel American, be patriotic, and defend America), hard boundaries (4 items: have citizenship, speak English, lived most life, and born in America), and religion (2 items: believe in God and be a Christian) as distinct components. Although religion sometimes is considered an aspect of nativism, and as such would contribute to setting hard boundaries of the 
American identity (Citrin et al., 1990, 1994), prior research revealed that for college students, the two religion items loaded on a distinct factor (Devos \& Banaji, 2005). Thus, the proposed threefactor structure was most consistent with a conceptual distinction between hard and soft boundaries that would not encompass religious references. The three-factor model fit the data satisfactorily $\left[\chi^{2}(62, N=807)=377.38, p<.001, \mathrm{RMSEA}=0.08(90 \% \mathrm{CI}: .07\right.$ to .09$), \mathrm{SRMR}=$ 0.06, CFI $=0.91, \mathrm{TLI}=.90, \mathrm{AIC}=36405.08]$. The standardized factor loadings were all significant $(p s<.01)$, and the factors were moderately and significantly correlated with each other $(.42<r s<.56)$.

To determine if the three-factor structure could be replicated across the three ethnic groups, we conducted multi-group confirmatory factor analyses. First, we used the three-factor model above as the restricted base model, and we tested this model against two unrestricted models in which 1) factor structures were free to vary across groups (configural invariance) and 2) factor loadings and intercepts were free to vary across groups (metric and scalar invariance, respectively). Both unrestricted models $\left[\chi^{2}(206, N=807)=585.25, p<.001, \mathrm{RMSEA}=0.08\right.$ $(90 \% \mathrm{CI}: .08$ to .09$), \mathrm{SRMR}=0.07, \mathrm{CFI}=0.90, \mathrm{TLI}=.88, \mathrm{AIC}=36191.33$ for unequal factor structures and $\chi^{2}(226, N=807)=686.78, p<.001, \mathrm{RMSEA}=0.09(90 \% \mathrm{CI}: .08$ to .10$), \mathrm{SRMR}$ $=0.10, \mathrm{CFI}=0.88, \mathrm{TLI}=.87, \mathrm{AIC}=36252.86$ for unequal factor loadings and intercepts $]$ fit the data significantly less well than the more parsimonious, restricted base model, $\Delta \chi^{2}(144, N=807)$ $=207.87, p<.001 ; \Delta \chi^{2}(164, N=807)=309.40, p<.001$. Therefore, we concluded that the three-factor model fit well across the three ethnic groups.

When attribute ratings were aggregated according to their contribution to a specific factor, mean attribute ratings across groups indicated that the definition of American identity included soft boundaries and hard boundaries, not religion (see Table 4 for correlations among 
soft and hard boundaries and other measured variables displayed separately by sample and ethnicity). Although European American participants consistently rated both soft and hard boundaries as more important to the definition of American identity than did Asian American and Latino/a participants (see tests of mean differences displayed in Table 3), the relative importance of these two dimensions was similar across ethnic groups. As a whole, these analyses revealed that to be a "true American" has a dual meaning. On one hand, the American identity is grounded in a commitment to liberal principles and an emotional attachment to the nation (soft boundaries). On the other hand, the American identity continues to include elements that are more consistent with a nativist conception (hard boundaries). Although both dimensions were deemed to be important, greater endorsement of soft boundaries than hard boundaries was clearly expressed. In addition, the data highlighted that there was a relative consensus across ethnic lines regarding the underlying structure and the relative importance of two distinct facets of the American identity. These findings support Hypothesis 1.

\section{Hypothesis 2: Perceived Ethnic Group Prototypicality}

To test our second hypothesis that perceptions of the relative prototypicality of ethnic groups should differ as a function of participants' ethnicity, we computed indices of dissimilarity from the superordinate category (i.e., American) for each target ethnic group (Sample A: Asian Americans and European Americans; Sample B: Latino Americans and Caucasian Americans). More precisely, we calculated the square root of the sum of squared attribute differences between the profiles of each target group and the superordinate category (for formulas, see Ullrich, 2009). Such an index of dissimilarity (or Euclidean distance) was computed separately for soft boundaries (using the 7 attributes structuring this dimension) and hard boundaries (using the 4 attributes structuring this dimension). Thus, each index represents how different from the "true 
American" prototype each target group was perceived to be (Table 5).

As an initial test of Hypothesis 2, we conducted paired-samples $t$-tests comparing the Euclidean distances by targets (Asian Americans and European Americans or Latino Americans and Caucasian Americans; Table 5). For European American participants, an ingroup prototypicality effect was obtained on both soft and hard boundaries. Minority participants did not reliably differentiate ethnic groups in terms of perceived prototypicality, with one exception. Indeed, Asian American participants displayed an outgroup prototypicality effect on soft boundaries, suggesting that they viewed civic values and emotional attachment to the nation as more characteristic of European Americans than of Asian Americans. This effect is somewhat counterintuitive because we did not find an effect in the same direction on hard boundaries.

To more directly test the hypothesized ethnic group differences on relative ingroup prototypicality, we computed indexes of relative ingroup prototypicality (RIP) by subtracting the dissimilarity index obtained for the ingroup from the dissimilarity index obtained for the outgroup (see Equation 1 in Ullrich, 2009). In Sample A, European American participants $(M=$ $0.49, S D=2.24)$ had significantly higher RIP scores on soft boundaries than Asian American participants $(M=-0.34, S D=2.30), t(359)=-3.48, p=.001 ; r=.18$. European American participants in Sample A $(M=0.75, S D=2.30)$ also had significantly higher RIP scores on hard boundaries than Asian American participants $(M=0.13, S D=2.26), t(359)=-2.60, p=.01 ; r=$ .14. Similarly, in Sample B, European American participants $(M=1.11, S D=2.67)$ had significantly higher RIP scores on soft boundaries than Latino/a participants $(M=-0.04, S D=$ 2.66), $t(444)=-4.54, p=7.35 \times 10^{-06} ; r=.21$. European American participants in Sample B $(M$ $=0.97, S D=2.80)$ also had significantly higher RIP scores on hard boundaries than Latino/a participants $(M=0.22, S D=2.43), t(444)=-3.03, p=.003 ; r=.14$. As predicted $($ Hypothesis 2$)$, 
European American participants displayed a more pronounced tendency to view their own group as embodying the American identity compared to Asian American and Latino/a participants, and this was true for both soft and hard boundaries.

\section{Hypothesis 3: Ethnic Group Prototypicality, Policy Attitudes, and Acculturation Ideologies}

With the exception of ethnic representation, European American participants reported more anti-minority attitudes and ideologies than Asian American or Latino/a participants (Table 3). To test our third hypothesis that relative ingroup prototypicality would predict such attitudes and ideologies for ethnic majority but not for ethnic minority group members, we operationalized prototypicality as the perceived similarity between a target group and the "true American" prototype (i.e., reverse-scored Euclidean distance for each target group; Ullrich, 2009). We correlated the relative ingroup prototypicality (RIP) index and then the prototypicality of each target ethnic group with policy attitudes and acculturation ideologies separately by participants' ethnicity (Table 6).

Focusing first on the relations between RIP and policy attitudes or acculturation ideologies, we found a very consistent pattern of results. For European American participants, RIP was related to more anti-minority policy attitudes and acculturation ideologies (out of 24 correlations, 19 were significant, 2 were marginal, and 2 were not significant). For Asian American and Latino/a participants, the vast majority of the correlations were not significant (11 out of 12 for Asian American participants and 9 out of 12 for Latino/a participants). The few reliable correlations suggested that for Asian American or Latino/a participants, greater relative ingroup prototypicality was linked to an endorsement of pro-minority policy attitudes (e.g., support for affirmative action or language policy) or acculturation ideologies (e.g., opposition to assimilation). We should note that RIP was reliably linked to attitudes toward ethnic 
representation only in one case (European American participants in Sample A on hard boundaries). Thus, we concluded that there was no clear support for our hypothesis on this specific policy. Not endorsing ethnic representation could be based on either an opposition to increased diversity or on the conviction that there should be more diversity in public services than there is in the constituents, and these opposing reasons may produce the null findings observed for this policy.

The patterns of correlations obtained suggest that the relative prototypicality of target ethnic groups is more systematically linked to policy attitudes and acculturation ideologies among European American participants than among Asian American or Latino/a participants. To provide a more direct test of Hypothesis 3, we conducted hierarchical regression analyses examining the interaction between participants' ethnicity and prototypicality as a predictor of policy attitudes and acculturation ideologies (Table 7). In these analyses, we examined the independent effects of the prototypicality of each target ethnic group (Asian Americans vs. European Americans for Sample A and Latino Americans vs. Caucasian Americans for Sample B) based on the assumption that they are not necessarily two sides of the same coin (see also Brewer, 1999; Ullrich, 2009). By simultaneously considering the prototypicality of both target groups, we can determine whether each of them uniquely accounts for policy attitudes and acculturation ideologies. This is particularly important because analyses conducted on the small sample of participants who completed the SDO scale (but not the policy attitudes or acculturation ideologies measures) revealed that SDO and RIP were correlated positively among European American participants $(.24<r s<.30)$ and negatively among Latino/a participants $(-.19<r s<-$ .38). More fine grained analyses showed that SDO was related only to ingroup prototypicality $(|.12|<r s<|.40|)$ but not to outgroup prototypicality $(.04<r s<.09) .^{3}$ Thus, we also can 
determine whether the findings can be reduced to variability in preference for group-based hierarchies or inequalities by examining separately the prototypicality perceptions of each target group. In these regression analyses (Table 7), most of the interactions were significant predictors of attitudes toward immigration $(|.13| \leq \beta \mathrm{s} \leq|.23|)$, language policy $(|.14| \leq \beta \mathrm{s} \leq|.22|)$, and affirmative action $(|.08| \leq \beta \mathrm{s} \leq|.17|)$. In other words, the ability of prototypicality perceptions to predict policy attitudes was significantly stronger for European American participants than for Asian American or Latino/a participants. A similar consistency in the pattern of results was not found for the interaction between participants' ethnicity and prototypicality perceptions predicting acculturation ideologies.

\section{Discussion}

Extending previous work on the American identity, we sought to determine the extent to which different ethnic groups are perceived to be prototypically American, and most importantly, to examine the relationships among ethnic group prototypicality, policy attitudes, and ideologies relevant to ethnic relations. In contrast to prior research focusing almost exclusively on the perspective of the ethnic majority group, our goal was to systematically compare patterns of responses displayed by ethnic majority and minority group members. The data support our hypotheses and show important convergences and divergences in the perspectives of those belonging to ethnic majority vs. minority groups. Using two relatively large samples of Asian American, European American, and Latino/a college students, we find evidence for a common definition of American identity across these three groups. Further, European Americans, in comparison to Asian Americans and Latino/as, are perceived as more aligned with this definition of American identity, especially by European Americans themselves. Finally, this propensity for European Americans to perceive their ingroup as embodying and the outgroup as not embodying 
characteristics of the "true American" is related to policy attitudes and ideologies that limit the rights and opportunities of ethnic minority groups, but this pattern of relations was virtually absent for ethnic minority group members.

First, regarding the definition of American identity, both soft boundaries (including civic values and emotional attachment to the nation) and hard boundaries are viewed as important components of being American, whereas religion is not part of the definition of a "true American." There is considerable consensus across ethnic lines on this definition of American identity. Although the relatively strong endorsement of hard boundaries in our sample is not unexpected given previous research findings, it is still striking given that we sampled a relatively young, privileged, and presumably liberal group of college students, most of whom were ethnic minority group members. Overall, the high level of agreement across ethnic groups suggests that there is a common frame of reference in defining what it means to be American, and as we discuss below, perceived differences between ethnic groups and their asymmetrical social standings may be rooted in this common referent.

Second, as expected, ethnic majority group members display ingroup prototypicality effects significantly more so than minority group members. These findings are in line with our predictions stemming from an integration of social dominance theory (Sidanius et al., 1997) and the ingroup projection model (Mummendey \& Wenzel, 1999). An important contribution of the present research is that European Americans are significantly more likely to perceive their own group as prototypically American than Asian Americans or Latino/as, whether ethnic groups are compared on hard or soft boundaries of the American identity. Majority group members emphasize the relative prototypicality of their group even on civic values and emotional attachment to the country (soft boundaries), suggesting that the effect is not limited to nativist 
elements (hard boundaries).

Third and most notably, there are divergent patterns of relations between ethnic group prototypicality and policy attitudes or acculturation ideologies for ethnic majority vs. minority group members. Consistent with the idea that perceived ethnic group prototypicality serves instrumental functions (Sindic \& Reicher, 2008), when European Americans maintain boundaries of American identity in a way that does not include ethnic minorities, it allows them to justify limiting the rights of these marginalized groups (Theiss-Morse, 2009). This finding has implications for the "black exceptionalism" hypothesis, which proposes that Asian Americans and Latino/as do not face the same rigid racial lines that African Americans endure due to the latter group's unique history in the US, and that the former two groups eventually would be able to assimilate into the social and political structure of mainstream American society (Sears \& Savalei, 2006). Although we do not have data on perceptions of African Americans in this study, the observed divergence in perspectives suggests that it may be difficult for Asian Americans and Latino/as to fully assimilate into mainstream American society. Members of these two groups, whether native-born or not, may self-identify as American, but they are not perceived as prototypically American, especially by majority group members. In addition, these prototypicality perceptions are linked to a wide range of policy attitudes and acculturation ideologies pertaining to ethnic minority groups in general, not just to Asian Americans and Latino/as, suggesting that ethnic group prototypicality plays an important role in understanding ethnic relations. Further research is needed to determine whether these identity boundaries may allow us to better explain European Americans' attitudes toward political issues pertaining to Asian Americans and Latino/as, whereas symbolic predispositions (Sears \& Savalei, 2006) may be the better explanation for European Americans' attitudes toward issues pertaining to African 
Americans, or whether some combination of ethnic group protypicality and symbolic predispositions provides a fuller understanding of the issues at hand.

For ethnic minorities, perceptions of ethnic group prototypicality may be independent from policy attitudes and acculturation ideologies concerning ethnic relations, also for instrumental reasons. Minority group members in our samples, like European Americans, may respond in a way that reflects the shared reality that "American $=$ White" when asked about the definition of American identity, without conceding that their group does not deserve the rights and benefits afforded to all Americans. Thus, ethnic minorities' attitudes about minority-related issues may be predicted by different factors, such as generation status, strength of ethnic or national identification, beliefs that existing social arrangements are unjust or oppressive, or racial socialization. In other words, the lack of reliable relations between ethnic group prototypicality and policy attitudes among Latino/a and Asian American participants suggests the need for further research to identify sources of variations in the perspective of ethnic minority group members. For example, it may be fruitful to examine these issues in samples of Asian American and Latino/a immigrants. Although we found no significant or meaningful differences between immigrants and non-immigrants in the present samples on any of the major study variables (effect size $r$ s for independent-samples $t$-tests of mean differences ranged from .02 to .11), the analyses were under-powered because of the rather small immigrant sample size. Taking into account generation status may allow us to better understand the null findings for ethnic minority group members. It also would be worth examining the extent to which ethnic and national identifications are sources of variations in attitudes toward policies or ideologies relevant to ethnic relations, and whether, once these variables are factored in, perceived ethnic group prototypicality plays a more potent role than what emerged in the present data. Based on the 
present dataset we cannot examine these questions, but our findings represent a useful step in documenting that the instrumental functions of perceived group prototypicality differ for ethnic majority vs. minority group members. Under some circumstances, individuals may be motivated to either emphasize or downplay differences in perceived prototypicality of groups (Sindic \& Reicher, 2008). Thus, it would be interesting to directly examine the fluidity of these perceptions as a function of group interests in future studies.

Potentially, the patterns of relations between prototypicality perceptions and antiminority attitudes or acculturation ideologies may stem from ethnic or individual differences in social dominance orientation (Sidanius \& Pratto, 1999; Sidanius \& Petrocik, 2001; Sidanius et al., 1997). Indeed, the degree of preference for inequality or hierarchy among social groups may account for both the tendency to view Europeans Americans as owning the nation and antiminority attitudes. Although we did not have the necessary data to control for SDO in the key analyses, the fact that SDO was related to ingroup prototypicality but not to outgroup prototypicality suggests that the findings cannot be reduced to differences in SDO. In particular, our findings regarding outgroup prototypicality are likely not explained by SDO. These results are in line with previous work showing that ingroup and outgroup prototypicality perceptions each have a unique predictive power (Waldzus et al., 2005; Wenzel et al., 2003). This said, it is likely that taking into account both SDO and ethnic group prototypicality ratings would enrich our understanding of anti-minority attitudes.

A limitation of the present study is the cross-sectional and correlational nature of the data, which do not allow for causal inferences. That is, it is not possible to determine whether perceptions of European Americans as the "true Americans" lead to anti-ethnic minority attitudes (or vice versa), or whether a third variable (e.g., SDO, political conservatism) leads to 
perceptions of prototypicality and policy attitudes. Future studies should use longitudinal or experimental designs to determine the direction of the relationship between perceptions of ethnic group prototypicality and attitudes toward policies concerning ethnic minorities. This said, our goal was not to provide evidence for a specific causal pathway, but to document a constellation of relations that captures important facets of American ethnic relations. In that sense, our findings highlight meaningful interconnections among perceived group prototypicality, policy attitudes, and acculturation ideologies.

Data were collected from mostly US-born undergraduate women students in a large metropolitan area on the West Coast, who are not representative of the general population. Therefore, the findings of this study may not generalize to populations differing in gender composition, age, education, generation status, socioeconomic status, or geographic region. Although the relatively small number of men across the two samples did not allow us to test our hypotheses separately for men vs. women, there were no systematic gender differences on the major variables (effect size $r$ f for independent-samples $t$-tests of mean differences ranged from .01 to .16). At this point, it is not possible to determine the generalizability of the current findings, but it might be the case that some of our results underestimate population effects, given that we sampled relatively young, privileged, and presumably liberal college students.

To better understand who is most likely to perceive the ingroup as more prototypical of the national identity than the outgroup and how those perceptions are intertwined with policy attitudes and acculturation ideologies, future studies also might examine the moderating roles of various constructs. For example, research using a national random sample showed that strong identifiers are most likely to set hard group boundaries and to help prototypical (but not marginalized) group members (Theiss-Morse, 2009). In addition, more ethnocentric individuals 
(those with more "readiness to partition the world into allies and adversaries") or more politically conservative individuals (those who place more importance on tradition, institutions, and authority) are more likely to define group membership in strict terms and defend group boundaries by holding negative attitudes toward non-prototypical group members, such as ethnic minorities who do not fit their definition of a "true American" (Kinder \& Kam, 2009). Thus, the role of prototypicality perceptions may differ as a function of national identification, ethnocentrism, or political conservatism.

Although most of our analyses emphasize the role of relative group prototypicality, there was evidence in the data that ingroup and outgroup prototypicality independently account for policy attitudes and acculturation ideologies. This is consistent with prior research, but it deserves more attention. In particular, teasing apart the role of these two pieces of the puzzle may help us to identify the respective contribution of motivational forces such as promoting ingroup interests (i.e., maximizing resources for the ingroup), hindering outgroup interests (i.e., limiting resources or opportunities for the outgroup), or maintaining group dominance (maximizing the relative advantages of the ingroup over the outgroup; see Lowery, Unzueta, Knowles, \& Goff, 2006). Additionally, prototypicality perceptions may be conflated with subgroup social statuses in the present analyses, such that ethnic majority group raters (i.e., European Americans) always rated lower status outgroup members, whereas ethnic minority group members (i.e., Asian Americans and Latino/as) always rated higher status outgroup members. To better understand the effect of ingroup-outgroup status on prototypicality perceptions without it being linked to group status, future studies should consider ratings of other minority target groups by ethnic minority group members (e.g., Asian Americans should rate their own group, European Americans, and Latino/as or African Americans). 
In sum, contrary to the popular image of a pluralistic and diverse US, it may be said that the American national identity is still characterized by a relative exclusion of group members who are not viewed as prototypically American, namely, ethnic minority group members. Our findings - that European Americans are perceived as most prototypical of the American identity and that this relative prototypicality predicts anti-minority policy attitudes and acculturation ideologies for European Americans - highlight possible mechanisms through which asymmetries of status and power between ethnic groups are maintained and full membership to the national identity and associated benefits are denied to ethnic minority group members. Thus, we have provided initial evidence for the assertion that for majority group members, relative ingroup prototypicality plays a central role in the relationship between beliefs about the American identity and ideologies or attitudes about minority rights. Most notably, our findings stand in stark contrast to the notion that only nativists or those who hold a highly restrictive definition of American identity use this definition to marginalize minority group members. Our findings suggest that majority group members perceive themselves to be more prototypicality American regardless of the content of the definition of American identity (i.e., whether it contains soft or hard boundaries). In other words, the more inclusive, soft boundaries of American identity are not so permeable, after all. 


\section{References}

Brewer, M. B. (1999). The psychology of prejudice: Ingroup love or outgroup hate? Journal of Social Issues, 55, 429-444.

Citrin, J., Haas, E. B., Muste, C., \& Reingold, B. (1994). Is American nationalism changing? Implications for foreign policy. International Studies Quarterly, 38, 1-31.

Citrin, J., Reingold, B., \& Green, D. P. (1990). American identity and the politics of ethnic change. Journal of Politics, 52, 1124-1152.

Deschamps, J. C. (1982). Social identity and relations of power between groups. In H. Tajfel (Ed.), Social identity and intergroup relations (pp. 85-98). Cambridge, MA: Cambridge.

Devos, T., \& Banaji, M. R. (2005). American = white? Journal of Personality and Social Psychology, 88, 447-466.

Devos, T., Gavin, K., \& Quintana, F. (2010). Say “Adios” to the American Dream: The interplay between ethnic and national identity among Latino and Caucasian Americans. Cultural Diversity and Ethnic Minority Psychology, 16, 37-49.

Hu, L., \& Bentler, P. M. (1999). Cutoff criteria for fit indices in covariance structure analysis: Conventional criteria versus new alternatives. Structural Equation Modeling, 6, 1-55.

Huynh, Q.-L., Devos, T., \& Smalarz, L. (2011). Perpetual foreigner in one's own land: Potential implications for identity and psychological adjustment. Journal of Social and Clinical Psychology, 30, 133-162.

Kessler, T., Mummendey, A., Funke, F., Brown, R., Binder, J., Zagefka, H., ... Maquil, A. (2010). We all live in Germany but ... Ingroup projection, group-based emotions and prejudice against immigrants. European Journal of Social Psychology, 40, 985-997.

Kinder, D. R., \& Kam, C. D. (2009). Us against them: Ethnocentric foundations of American opinion. Chicago, IL: University of Chicago.

Levin, S., Matthews, M., Guimond, S., Sidanius, J., Pratto, F., Kteily, N., ... Dover, T. (2012). Assimilation, multiculturalism, and colorblindness: Mediated and moderated relationships between social dominance orientation and prejudice. Journal of 
Experimental Social Psychology, 48, 207-212.

Li, Q., \& Brewer, M. B. (2004). What does it mean to be an American? Patriotism, nationalism, and American identity after 9/11. Political Psychology, 25, 727-739.

Lowery, B. S., Unzueta, M. M., Knowles, E. D., \& Goff, P. A. (2006). Concern for the in-group and opposition to affirmative action. Journal of Personality and Social Psychology, 90, 961-974.

Mukherjee, S., Molina, L. E., \& Adams, G. (2012). National identity and immigration policy: Concern for legality or ethnocentric exclusion? Analyses of Social Issues and Public Policy, 12, 21-32.

Mummendey, A., \& Wenzel, M. (1999). Social discrimination and tolerance in intergroup relations: Reactions to intergroup difference. Personality and Social Psychology Review, $3,158-174$.

Muthén, L. K. \& Muthén, B. O. (2007). Mplus 5.1 [Computer software]. Los Angeles, CA: Muthén \& Muthén.

Pratto, F., Sidanius, J., Stallworth, L. M., \& Malle, B. F. (1994). Social dominance orientation: A personality variable predicting social and political attitudes. Journal of Personality and Social Psychology, 67, 741-763.

Pehrson, S., \& Green, E. G. T. (2010). Who we are and who can join us: National identity content and entry criteria for new immigrants. Journal of Social Issues, 66, 695-716.

Reese, G., Berthold, A., \& Steffens, M. C. (2012). We are the world - and they are not: Prototypicality for the world community, legitimacy, and responses to global inequality. Political Psychology, 33, 683-700.

Ryan, C. S., Hunt, J. S., Weible, J. A., Peterson, C. R., \& Casas, J. F. (2007). Multicultural and colorblind ideology, stereotypes, and ethnocentrism among Black and White Americans. Group Processes and Intergroup Relations, 10, 617-637.

Schatz, R. T., Staub, E., \& Lavine, H. (1999). On the varieties of national attachment: Blind versus constructive patriotism. Political Psychology, 20, 151-174.

Schildkraut, D. J. (2007). Defining American identity in the twenty-first century: How much 
"there" is there? The Journal of Politics, 69, 597-615.

Sears, D. O., Citrin, J., Cheleden, S. V., \& van Laar, C. (1999). Cultural diversity and multicultural politics: Is ethnic balkanization psychologically inevitable? In D. A. Prentice \& D. T. Miller (Eds.), Cultural divides: Understanding and overcoming group conflict (pp. 35-79). New York, NY: Russell Sage Foundation.

Sears, D. O., \& Savalei, V. (2006). The political color line in America: Many "peoples of color" or Black exceptionalism? Political Psychology, 27, 895-924.

Sidanius, J., Feshbach, S., Levin, S., \& Pratto, F. (1997). The interface between ethnic and national attachment: Ethnic pluralism or ethnic dominance? Public Opinion Quarterly, $61,102-133$.

Sidanius, J., \& Pratto, F. (1999). Social dominance: An intergroup theory of social hierarchy and oppression. Cambridge, MA: Cambridge.

Sidanius, J., \& Petrocik, J. R. (2001). Communal and national identity in a multiethnic state: A comparison of three perspectives. In R. D. Ashmore, L. Jussim, \& D. Wilder (Eds.), Social identity, intergroup conflict, and conflict reduction (pp. 101-129). New York, NY: Oxford.

Sindic, D., \& Reicher, S. D. (2008). The instrumental use of group prototypicality judgments. Journal of Experimental Social Psychology, 44, 1425-1435.

Theiss-Morse, E. (2009). Who counts as an American? The boundaries of national identity. New York, NY: Cambridge.

Turner, J. C., Hogg, M. A., Oakes, P. J., Reicher, S. D., \& Wetherell, M. S. (1987). Rediscovering the social group: A self-categorization theory. Oxford, England: Blackwell.

Ullrich, J. (2009). Reconsidering the "relative" in relative ingroup prototypicality. European Journal of Social Psychology, 39, 299-310.

Waldzus, S., Mummendey, A., \& Wenzel, M. (2005). When "different" means "worse": Ingroup prototypicality in changing intergroup contexts. Journal of Experimental Social Psychology, 41, 76-83. 
Waldzus, S., Mummendey, A., Wenzel, M., \& Boettcher, F. (2004). Of bikers, teachers, and Germans: Groups' diverging views about their prototypicality. British Journal of Social Psychology, 43, 385-400.

Weber, U., Mummendey, A., \& Waldzus, S. (2002). Perceived legitimacy of intergroup status differences: Its prediction by relative ingroup prototypicality. European Journal of Social Psychology, 32, 449-470.

Wenzel, M., Mummendey, A., \& Waldzus, S. (2007). Superordinate identities and intergroup conflict: The ingroup projection model. European Review of Social Psychology, 18, 331372.

Wenzel, M., Mummendey, A., Weber, U., \& Waldzus, S. (2003). The ingroup as pars pro toto: Projection from the ingroup onto the inclusive category as a precursor to social discrimination. Personality and Social Psychology Bulletin, 29, 461-473.

Wolsko, C., Park, B., \& Judd, C. M. (2006). Considering the Tower of Babel: Correlates of assimilation and multiculturalism among ethnic minority and majority groups in the United States. Social Justice Research, 19, 277-306.

Wright, M., Citrin, J., \& Wand, J. (2012). Alternative measures of American national identity: Implications for the civic-ethnic distinction. Political Psychology, 33, 469-482. 


\section{Footnotes}

${ }^{1}$ A copy of all measures is available from the first author upon request.

${ }^{2}$ We used the target label Caucasian Americans in Sample B because this term is commonly used to describe non-Hispanic Americans of European descent, and it is unambiguous when contrasted to Latino Americans. This label was chosen over alternatives, including Whites, which may be problematic given that many Latinos consider themselves White, and European Americans, which is not optimal given the historical influence of Spain on many Latin American countries.

${ }^{3}$ It was not possible to include SDO as a covariate in the regression analyses reported above because the subset of participants who completed the SDO scale did not complete the policy attitudes measures. 
Table 1

Participant Demographics by Sample and Ethnicity

\begin{tabular}{|c|c|c|c|c|}
\hline & \multicolumn{2}{|c|}{ Sample A } & \multicolumn{2}{|c|}{ Sample B } \\
\hline & Asian Americans & European Americans & Latino/as & European Americans \\
\hline$N$ & 182 & 179 & 219 & 227 \\
\hline$\%$ Female & 70.30 & 77.10 & 70.80 & 72.70 \\
\hline Citizenship (\% US) & 100.00 & 100.00 & 100.00 & 99.10 \\
\hline Country of birth (\% US) & 81.90 & 97.80 & 88.60 & 98.20 \\
\hline Age range & 18 to 27 & 17 to 46 & 17 to 42 & 17 to 38 \\
\hline Age $M(S D)$ & $18.88(1.45)$ & $19.19(2.76)$ & $19.28(2.37)$ & $19.47(2.30)$ \\
\hline \multicolumn{5}{|l|}{ Year in school (\%) } \\
\hline First & 65.93 & 59.78 & 59.82 & 55.07 \\
\hline Second & 15.93 & 17.88 & 16.44 & 24.67 \\
\hline Third & 9.34 & 12.85 & 10.50 & 9.69 \\
\hline Fourth or beyond & 8.24 & 8.38 & 11.87 & 10.57 \\
\hline
\end{tabular}

Note. There were 2 Asian American and 3 Latino/a participants who did not provide their country of birth; the percentage shown is based on completed country of birth data only. For some groups, year in school percentages do not sum to 100 because of missing values. 
Table 2

Common Definition of the American Identity: Ratings of the "True American" Attributes by Sample and Ethnicity

\begin{tabular}{|c|c|c|c|c|c|c|c|c|}
\hline \multirow[b]{3}{*}{ Item } & \multicolumn{4}{|c|}{ Sample A } & \multicolumn{4}{|c|}{ Sample B } \\
\hline & \multicolumn{2}{|c|}{$\begin{array}{c}\text { Asian } \\
\text { Americans }\end{array}$} & \multicolumn{2}{|c|}{ European Americans } & \multicolumn{2}{|c|}{ Latino/as } & \multicolumn{2}{|c|}{ European Americans } \\
\hline & $M(S D)$ & Rank & $M(S D)$ & Rank & $M(S D)$ & Rank & $M(S D)$ & Rank \\
\hline Treat all races, backgrounds equally & $6.13(1.18)$ & 1 & $6.16(1.20)$ & 2 & $5.95(1.43)$ & 1 & $6.03(1.27)$ & 2 \\
\hline Have American citizenship & $5.62(1.56)$ & 2 & $6.33(1.03)$ & 1 & $5.25(1.79)$ & 4 & $6.04(1.29)$ & 1 \\
\hline Vote in elections & $5.51(1.39)$ & 5 & $5.84(1.18)$ & 4 & $5.46(1.71)$ & 3 & $5.83(1.42)$ & 3 \\
\hline Respect political institutions \& laws & $5.58(1.29)$ & 3 & $5.79(1.24)$ & 5 & $5.55(1.49)$ & 2 & $5.64(1.33)$ & 5 \\
\hline Feel American & $5.53(1.62)$ & 4 & $5.76(1.45)$ & 6 & $5.23(1.72)$ & 5 & $5.69(1.35)$ & 4 \\
\hline Be able to speak English & $5.47(1.57)$ & 6 & $5.91(1.50)$ & 3 & $4.95(1.83)$ & 7 & $5.62(1.59)$ & 6 \\
\hline Get ahead on own effort & $5.13(1.36)$ & 8 & $5.32(1.38)$ & 8 & $5.12(1.55)$ & 6 & $5.34(1.32)$ & 7 \\
\hline Be patriotic & $5.16(1.35)$ & 7 & $5.55(1.46)$ & 7 & $4.72(1.78)$ & 8 & $5.20(1.62)$ & 8 \\
\hline Defend America when criticized & $5.06(1.52)$ & 9 & $5.32(1.76)$ & 9 & $4.69(1.81)$ & 9 & $5.13(1.66)$ & 9 \\
\hline Lived in America most of one's life & $4.08(1.89)$ & 10 & $4.68(1.84)$ & 10 & $4.31(1.90)$ & 10 & $4.57(1.83)$ & 10 \\
\hline Born in America & $3.74(1.92)$ & 11 & $4.19(2.01)$ & 11 & $3.81(2.14)$ & 11 & $3.89(2.05)$ & 11 \\
\hline Believe in God & $3.08(1.88)$ & 12 & $2.75(1.80)$ & 12 & $3.05(2.09)$ & 12 & $2.89(1.87)$ & 12 \\
\hline Be a Christian & $2.65(1.79)$ & 13 & $2.35(1.52)$ & 13 & $2.37(1.61)$ & 13 & $2.50(1.80)$ & 13 \\
\hline
\end{tabular}


Table 3

Means, Standard Deviations, and Score Reliability for Definition of American Identity, Policy Attitudes, and Acculturation Ideologies by Sample and Ethnicity

\begin{tabular}{|c|c|c|c|c|c|c|c|c|c|c|c|c|}
\hline & \multicolumn{6}{|c|}{ Sample A } & \multicolumn{6}{|c|}{ Sample B } \\
\hline & \multicolumn{2}{|c|}{ Asian Americans } & \multicolumn{2}{|c|}{$\begin{array}{c}\text { European } \\
\text { Americans }\end{array}$} & \multirow[b]{2}{*}{$p$} & \multirow[b]{2}{*}{$r$} & \multicolumn{2}{|c|}{ Latino/as } & \multicolumn{2}{|c|}{$\begin{array}{l}\text { European } \\
\text { Americans }\end{array}$} & \multirow[b]{2}{*}{$p$} & \multirow[b]{2}{*}{$r$} \\
\hline & $M(S D)$ & $\alpha$ & $M(S D)$ & $\alpha$ & & & $M(S D)$ & $\alpha$ & $M(S D)$ & $\alpha$ & & \\
\hline$N$ & 182 & & 179 & & & & 219 & & 227 & & & \\
\hline Soft Boundaries & $5.44(0.91)$ & .77 & $5.68(0.89)$ & .75 & .02 & .13 & $5.25(1.17)$ & .83 & $5.55(0.94)$ & .78 & .003 & .15 \\
\hline Hard Boundaries & $4.73(1.33)$ & .76 & $5.28(1.26)$ & .78 & $6.68 \times 10^{-05}$ & .21 & $4.58(1.49)$ & .78 & $5.03(1.33)$ & .78 & .001 & .16 \\
\hline \multicolumn{13}{|l|}{ Policy Attitudes } \\
\hline$N$ & 135 & & 111 & & & & 103 & & 95 & & & \\
\hline Immigration & $3.08(0.68)$ & .73 & $2.55(0.82)$ & .81 & $1.85 \times 10^{-07}$ & .35 & $3.53(0.68)$ & .75 & $2.65(0.84)$ & .82 & $9.43 \times 10^{-14}$ & .51 \\
\hline Language Policy & $3.29(0.67)$ & .75 & $2.93(0.89)$ & .75 & .001 & .24 & $3.65(0.69)$ & .75 & $3.00(0.84)$ & .86 & $1.04 \times 10^{-08}$ & .39 \\
\hline Affirmative Action & $3.05(0.58)$ & .65 & $2.84(0.76)$ & .82 & .02 & .17 & $3.23(0.62)$ & .66 & $2.71(0.66)$ & .73 & $3.70 \times 10^{-08}$ & .38 \\
\hline Ethnic Representation & $2.00(0.62)$ & .71 & $1.88(0.55)$ & .69 & .12 & .10 & $2.04(0.59)$ & .54 & $2.00(0.53)$ & .54 & .63 & .03 \\
\hline \multicolumn{13}{|l|}{ Acculturation Ideologies } \\
\hline$N$ & 135 & & 111 & & & & 103 & & 95 & & & \\
\hline Multiculturalism & $4.09(0.46)$ & .72 & $3.89(0.46)$ & .70 & .001 & .22 & $4.07(0.50)$ & .73 & $3.89(0.57)$ & .82 & .02 & .17 \\
\hline
\end{tabular}

Note. $p$ and effect size $r$ values correspond to analyses comparing different ethnic groups within samples (i.e., Sample A: Asian

Americans vs. European Americans, Sample B: Latino/as vs. European Americans). 
Table 4

Correlations among Definition of American Identity, Policy Attitudes, and Acculturation Ideologies by Sample and Ethnicity

\begin{tabular}{|c|c|c|c|c|c|c|c|c|}
\hline & 1 & 2 & 3 & 4 & 5 & 6 & 7 & 8 \\
\hline \multicolumn{9}{|c|}{ Sample A: Asian Americans and European Americans } \\
\hline 1. Soft Boundaries & - & .40 & -.10 & -.15 & -.13 & -.09 & .20 & -.01 \\
\hline 2. Hard Boundaries & .37 & - & -.19 & -.11 & -.13 & .19 & .11 & -.14 \\
\hline 3. Immigration & -.35 & -.55 & - & .36 & .28 & -.04 & -.57 & .34 \\
\hline 4. Language Policy & -.34 & -.59 & .73 & - & .25 & -.06 & -.70 & .40 \\
\hline 5. Affirmative Action & -.34 & -.53 & .60 & .69 & - & -.03 & -.67 & .40 \\
\hline 6. Ethnic Representation & .09 & .12 & .09 & -.01 & .04 & - & .16 & -.31 \\
\hline 7. Assimilation & .41 & .52 & -.20 & -.41 & -.31 & -.02 & - & -.43 \\
\hline 8. Multiculturalism & -.10 & -.26 & .14 & .25 & .10 & -.35 & -.13 & - \\
\hline \multicolumn{9}{|c|}{ Sample B: Latino/as and European Americans } \\
\hline 1. Soft Boundaries & - & .45 & .10 & .04 & -.17 & -.30 & .40 & .36 \\
\hline 2. Hard Boundaries & .37 & - & -.08 & -.25 & -.21 & -.12 & .27 & -.08 \\
\hline 3. Immigration & -.14 &.- .33 & - & .45 & .34 & -.09 & -.44 & .31 \\
\hline 4. Language Policy & -.31 & -.50 & .59 & - & .38 & -.24 & -.70 & .41 \\
\hline 5. Affirmative Action & -.18 &.- .44 & .48 & .61 & - & -.14 & -.60 & .44 \\
\hline 6. Ethnic Representation & .05 & .09 & -.18 & -.21 & -.20 & - & .05 & -.27 \\
\hline 7. Assimilation & .51 & .46 & .00 & -.42 & -.51 & -.06 & - & -.26 \\
\hline 8. Multiculturalism & .19 & -.19 & .28 & .31 & .10 & -.42 & .20 & - \\
\hline
\end{tabular}

Note. Sample A correlations for Asian Americans are above the diagonal $(n=135)$, and correlations for European Americans are below the diagonal $(n=111)$. Sample B correlations for Latino/as are above the diagonal $(n=103)$, and correlations for European Americans are below the diagonal $(n=95)$. Correlations significant at $p<.05$ (2-tailed) are in italicized font, and correlations significant at $p<.01$ (2-tailed) are in bold font. 
Table 5

Relative Ethnic Group Prototypicality: Paired-Samples t-tests Comparing Ratings of Different Target Ethnic Groups by Rater Ethnicity

\begin{tabular}{|c|c|c|c|c|c|c|c|c|}
\hline \multirow[b]{2}{*}{ Factor } & \multirow[b]{2}{*}{ Rater Ethnicity } & \multirow[b]{2}{*}{ Target Ethnic Group } & \multicolumn{2}{|c|}{$\begin{array}{c}\text { Euclidean } \\
\text { Distance }\end{array}$} & \multirow[b]{2}{*}{$t$} & \multirow[b]{2}{*}{$d f$} & \multirow[b]{2}{*}{$p$} & \multirow{2}{*}{$\begin{array}{l}\text { Effect } \\
\text { Size } r\end{array}$} \\
\hline & & & $M$ & $S D$ & & & & \\
\hline \multirow{2}{*}{ Soft Boundaries } & \multirow{2}{*}{ Asian American } & Asian Americans & 5.25 & 2.22 & \multirow{2}{*}{2.01} & \multirow{2}{*}{181} & \multirow{2}{*}{.05} & \multirow{2}{*}{.21} \\
\hline & & European Americans & 4.91 & 1.99 & & & & \\
\hline \multirow{14}{*}{ Hard Boundaries } & \multirow{2}{*}{ European American (A) } & Asian Americans & 5.38 & 2.19 & \multirow{2}{*}{2.92} & \multirow{2}{*}{178} & \multirow{2}{*}{.004} & \multirow{2}{*}{.31} \\
\hline & & European Americans & 4.89 & 1.93 & & & & \\
\hline & \multirow{2}{*}{ Latino/a } & Latino Americans & 5.47 & 2.19 & \multirow{2}{*}{0.22} & \multirow{2}{*}{218} & \multirow{2}{*}{.83} & \multirow{2}{*}{.02} \\
\hline & & Caucasian Americans & 5.43 & 2.25 & & & & \\
\hline & \multirow{2}{*}{ European American (B) } & Latino Americans & 5.73 & 2.61 & \multirow{2}{*}{6.24} & \multirow{2}{*}{226} & \multirow{2}{*}{$2.12 \times 10^{-09}$} & \multirow{2}{*}{.59} \\
\hline & & Caucasian Americans & 4.62 & 2.13 & & & & \\
\hline & \multirow{2}{*}{ Asian American } & Asian Americans & 3.94 & 1.83 & \multirow{2}{*}{-0.75} & \multirow{2}{*}{181} & \multirow{2}{*}{.45} & \multirow{2}{*}{.08} \\
\hline & & European Americans & 4.07 & 2.17 & & & & \\
\hline & \multirow{2}{*}{ European American (A) } & Asian Americans & 4.28 & 2.06 & 436 & & $0^{-05}$ & \\
\hline & & European Americans & 3.53 & 2.02 & 4.36 & 178 & 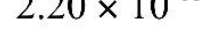 & .46 \\
\hline & I ating/a & Latino Americans & 4.29 & 2.05 & -132 & 218 & 10 & 13 \\
\hline & Latino/a & Caucasian Americans & 4.51 & 2.31 & -1.32 & 218 & .19 & .13 \\
\hline & European American (B) & Latino Americans & 4.72 & 2.13 & 5.24 & 226 & $3.75 \times 10^{-07}$ & 49 \\
\hline & European American (B) & Caucasian Americans & 3.75 & 2.16 & 5.24 & 226 & $3.15 \times 10$ & .49 \\
\hline
\end{tabular}

Note . Euclidean distance $=$ how different from the "true American" prototype each target ethnic group is perceived to be (higher distance means more different). Asian Americans: $N=182$; European Americans (A) = European Americans from Sample A: $N=$ 179; Latino/as: $N=219$; European Americans (B) = European Americans from Sample B: $N=227$. 
Table 6

Ethnic Group Prototypicality Correlated with Policy Attitudes and Acculturation Ideologies by Rater Ethnicity

\begin{tabular}{|c|c|c|c|c|c|c|c|c|c|c|c|c|c|c|}
\hline \multirow[b]{2}{*}{ Factor } & \multirow{2}{*}{$\begin{array}{l}\text { Rater } \\
\text { Ethnicity }\end{array}$} & \multirow{2}{*}{$\begin{array}{l}\text { Target } \\
\text { Group } \\
\text { Ethnicity }\end{array}$} & \multicolumn{2}{|c|}{ Immigration } & \multicolumn{2}{|c|}{ Language Policy } & \multicolumn{2}{|c|}{$\begin{array}{l}\text { Affirmative } \\
\text { Action }\end{array}$} & \multicolumn{2}{|c|}{$\begin{array}{c}\text { Ethnic } \\
\text { Representation }\end{array}$} & \multicolumn{2}{|c|}{ Assimilation } & \multicolumn{2}{|c|}{ Multiculturalism } \\
\hline & & & $r$ & $p$ & $r$ & $p$ & $r$ & $p$ & $r$ & $p$ & $r$ & $p$ & $r$ & $p$ \\
\hline \multirow{11}{*}{$\begin{array}{l}\text { Soft } \\
\text { Boundaries }\end{array}$} & Asian Am. & RIP & -.01 & .93 & .10 & .24 & .02 & .79 & .003 & .97 & .05 & .60 & .02 & .86 \\
\hline & & Asian Am. & .05 & .59 & .08 & .35 & .04 & .69 & .16 & .06 & .03 & .77 & -.14 & .11 \\
\hline & & Euro. Am. & .06 & .47 & -.02 & .82 & .01 & .88 & .18 & .04 & -.02 & .80 & -.18 & .04 \\
\hline & Euro. Am. (A) & RIP & -.47 & $1.45 \times 10^{-7}$ & -.42 & $3.98 \times 10^{-6}$ & -.46 & $3.17 \times 10^{-7}$ & .17 & .08 & .43 & $3.18 \times 10^{-6}$ & -.38 & $4.29 \times 10^{-5}$ \\
\hline & & Asian Am. & .29 & .002 & .41 & $9.29 \times 10^{-6}$ & .39 & $2.61 \times 10^{-5}$ & -.05 & .61 & -.22 & .02 & .25 & .01 \\
\hline & & Euro. Am. & -.26 & .01 & -.05 & .63 & -.13 & .19 & .16 & .10 & .29 & .002 & -.18 & .06 \\
\hline & & Lat. Am. & -.10 & .33 & .07 & .51 & -.11 & .28 & .17 & .09 & -.08 & .44 & -.10 & .34 \\
\hline & & Cauc. Am. & .05 & .65 & -.12 & .21 & -.25 & .01 & .04 & .67 & .30 & .00 & .07 & .47 \\
\hline & Euro. Am. (B) & RIP & -.30 & .003 & -.44 & $7.10 \times 10^{-6}$ & -.52 & $7.67 \times 10^{-8}$ & .20 & .06 & .49 & $3.94 \times 10^{-7}$ & $\begin{array}{l}.07 \\
-.14\end{array}$ & .19 \\
\hline & & Lat. Am. & .17 & .10 & .21 & .04 & .34 & .00 & -.05 & .67 & -.28 & .01 & -.05 & .62 \\
\hline & & Cauc. Am. & -.17 & .10 & -.31 & .002 & -.23 & .03 & .20 & .05 & .28 & .01 & -.25 & .01 \\
\hline \multirow{11}{*}{$\begin{array}{l}\text { Hard } \\
\text { Boundaries }\end{array}$} & Asian Am. & RIP & .07 & .42 & .02 & .86 & .19 & .03 & -.09 & .31 & .03 & .74 & .02 & .81 \\
\hline & & Asian Am. & .001 & .99 & .02 & .82 & .23 & .01 & .02 & .78 & .01 & .88 & -.09 & .30 \\
\hline & & Euro. Am. & -.07 & .43 & .001 & .99 & .003 & .97 & .11 & .21 & -.02 & .84 & -.10 & .26 \\
\hline & & Asian Am. & .21 & .03 & .30 & .001 & .13 & .19 & -.04 & .69 & -.25 & .01 & .09 & .36 \\
\hline & & Euro. Am. & -.40 & $1.50 \times 10^{-5}$ & -.32 & .001 & -.33 & .0004 & .19 & .05 & .35 & .0002 & -.20 & .03 \\
\hline & Latino/a & RIP & -.06 & .56 & .22 & .03 & .19 & .05 & .05 & .62 & -.29 & .003 & .005 & .96 \\
\hline & & Lat. Am. & -.20 & .05 & .04 & .66 & .07 & .48 & .11 & .28 & -.20 & .04 & -.04 & .67 \\
\hline & & Cauc. Am. & -.13 & .19 & -.21 & .03 & -.15 & .13 & .05 & .61 & .14 & .16 & -.05 & .63 \\
\hline & Euro. Am. (B) & RIP & -.40 & $6.63 \times 10^{-5}$ & -.44 & $6.98 \times 10^{-6}$ & -.52 & $7.82 \times 10^{-8}$ & .14 & .18 & .43 & $1.21 \times 10^{-5}$ & -.19 & .06 \\
\hline & & Lat. Am. & .27 & .01 & .23 & .02 & .45 & $6.13 \times 10^{-6}$ & -.09 & .38 & -.28 & .01 & .01 & .90 \\
\hline & & Cauc. Am. & -.29 & .01 & -.39 & $8.45 \times 10^{-5}$ & -.27 & .01 & .10 & .33 & .33 & .001 & -.27 & .01 \\
\hline
\end{tabular}

Note. To aid in interpretation, correlations significant at $p<.05$ (2-tailed) are in italicized font, and correlations significant at $p<.01$ (2-tailed) are in bold font. RIP = relative ingroup prototypicality (ingroup prototypicality minus outgroup prototypicality). Asian Am. $=$ Asian Americans $(N=135)$, Euro. Am. $(\mathrm{A})=$ European Americans from Sample A $(N=111)$, Latino/as $(N=103)$, Euro. Am. $(\mathrm{B})=$

European Americans from Sample B $(N=95)$. 
Table 7

Policy Attitudes and Acculturation Ideologies Regressed on Rater Ethnicity, Ethnic Group Prototypicality, and the Interactions among These Variables

\begin{tabular}{|c|c|c|c|c|c|c|c|c|c|c|c|c|c|c|}
\hline \multirow[b]{2}{*}{ Factor } & \multirow[b]{2}{*}{ Sample } & \multirow{2}{*}{$\begin{array}{l}\text { Predictor } \\
\text { Variable }\end{array}$} & \multicolumn{2}{|c|}{ Immigration } & \multicolumn{2}{|c|}{ Language Policy } & \multicolumn{2}{|c|}{ Affirmative Action } & \multicolumn{2}{|c|}{$\begin{array}{c}\text { Ethnic } \\
\text { Representation }\end{array}$} & \multicolumn{2}{|c|}{ Assimilation } & \multicolumn{2}{|c|}{ Multiculturalism } \\
\hline & & & $\beta$ & $p$ & $\beta$ & $p$ & $\beta$ & $p$ & $\beta$ & $p$ & $\beta$ & $p$ & $\beta$ & $p$ \\
\hline Soft & \multirow{5}{*}{ A } & Ethnicity & .31 & $1.84 \times 10^{-7}$ & .20 & .001 & .13 & .03 & .11 & .09 & -.03 & .69 & .20 & .001 \\
\hline \multirow[t]{9}{*}{ Boundaries } & & AA Prototyp. & .44 & $1.97 \times 10^{-6}$ & .53 & $3.61 \times 10^{-8}$ & .55 & $2.00 \times 10^{-8}$ & -.11 & .29 & -.39 & $7.95 \times 10^{-5}$ & .35 & .0003 \\
\hline & & EA Prototyp. & -.45 & $5.43 \times 10^{-6}$ & -.24 & .02 & -.34 & .001 & .20 & .07 & .47 & $6.91 \times 10^{-6}$ & -.31 & .002 \\
\hline & & $\begin{array}{l}\text { Ethnicity } x \\
\text { AA Prototyp. }\end{array}$ & -.16 & .0008 & -.17 & .001 & -.17 & $9.18 \times 10^{-5}$ & .06 & .13 & .12 & .001 & -.10 & .002 \\
\hline & & $\begin{array}{l}\text { Ethnicity } x \\
\text { EA Prototyp. }\end{array}$ & .20 & .0001 & .08 & .16 & .12 & .01 & -.02 & .68 & -.15 & .0002 & .04 & .18 \\
\hline & \multirow{5}{*}{ B } & Ethnicity & .46 & $3.93 \times 10^{-12}$ & .31 & $1.64 \times 10^{-6}$ & .31 & $2.32 \times 10^{-6}$ & .07 & .36 & -.14 & .03 & .13 & .07 \\
\hline & & L Prototyp. & .24 & .006 & .35 & $8.34 \times 10^{-5}$ & .43 & $8.84 \times 10^{-7}$ & -.12 & .23 & -.39 & $1.70 \times 10^{-5}$ & .05 & .61 \\
\hline & & EA Prototyp. & -.28 & .006 & -.49 & $3.24 \times 10^{-6}$ & -.43 & $3.14 \times 10^{-5}$ & .25 & .03 & .46 & $1.62 \times 10^{-5}$ & -.30 & .0095 \\
\hline & & $\begin{array}{l}\text { Ethnicity x L } \\
\text { Prototyp. }\end{array}$ & -.14 & .01 & -.10 & .06 & -.16 & .0003 & .09 & .04 & .07 & .13 & -.05 & .24 \\
\hline & & $\begin{array}{l}\text { Ethnicity x } \\
\text { EA Prototyp. }\end{array}$ & .15 & .01 & .15 & .007 & .08 & .10 & -.07 & .11 & -.04 & .33 & .11 & .0098 \\
\hline Hard & \multirow{5}{*}{ A } & Ethnicity & .28 & $1.36 \times 10^{-6}$ & .17 & .003 & .10 & .09 & .12 & .06 & -.004 & .94 & .20 & .002 \\
\hline \multirow[t]{9}{*}{ Boundaries } & & AA Prototyp. & .38 & $8.20 \times 10^{-6}$ & .48 & $4.13 \times 10^{-8}$ & .28 & .002 & -.10 & .30 & -.42 & $3.52 \times 10^{-6}$ & .16 & .08 \\
\hline & & EA Prototyp. & -.57 & $2.40 \times 10^{-9}$ & -.55 & $1.30 \times 10^{-8}$ & -.49 & $8.03 \times 10^{-7}$ & .21 & .04 & .55 & $5.80 \times 10^{-8}$ & -.27 & .009 \\
\hline & & $\begin{array}{l}\text { Ethnicity } \mathrm{x} \\
\text { AA Prototyp. }\end{array}$ & -.13 & .005 & -.18 & .0003 & -.01 & .83 & .02 & .63 & .13 & .001 & -.05 & .10 \\
\hline & & $\begin{array}{l}\text { Ethnicity x } \\
\text { EA Prototyp. }\end{array}$ & .19 & $7.31 \times 10^{-5}$ & .22 & $2.18 \times 10^{-5}$ & .13 & .003 & -.03 & .52 & -.16 & $1.84 \times 10^{-5}$ & .05 & .14 \\
\hline & \multirow{5}{*}{ B } & Ethnicity & .44 & $1.21 \times 10^{-11}$ & .30 & $6.68 \times 10^{-6}$ & .28 & $1.61 \times 10^{-5}$ & .05 & .50 & -.13 & .07 & .12 & .09 \\
\hline & & L Prototyp. & .26 & .002 & .24 & .005 & .42 & $1.75 \times 10^{-6}$ & -.09 & .39 & -.27 & .004 & .02 & .82 \\
\hline & & EA Prototyp. & -.28 & .001 & -.41 & $8.37 \times 10^{-6}$ & -.27 & .003 & .10 & .35 & .33 & .001 & -.28 & .005 \\
\hline & & $\begin{array}{l}\text { Ethnicity x L } \\
\text { Prototyp. }\end{array}$ & -.17 & .002 & -.05 & .33 & -.10 & .03 & .06 & .19 & -.01 & .85 & -.01 & .72 \\
\hline & & $\begin{array}{l}\text { Ethnicity } \mathrm{x} \\
\text { EA Prototyp. }\end{array}$ & .11 & .07 & .09 & .13 & .04 & .48 & -.02 & .60 & -.04 & .47 & .07 & .09 \\
\hline
\end{tabular}

Note. Sample A = Asian Americans and European Americans: $N=246$; Sample B = Latino/as and European Americans: $N=198$. Ethnicity is a dummy coded variable where European American $=0$, minority group $=1 ; \mathrm{AA}=$ Asian American, $\mathrm{EA}=$ European American, $\mathrm{L}=\mathrm{Latino} / \mathrm{a}$, Prototyp. $=$ Group prototypicality; italicized font $=p<.05$; bold font $=p<.01$. 